\title{
Sar Schnu
}




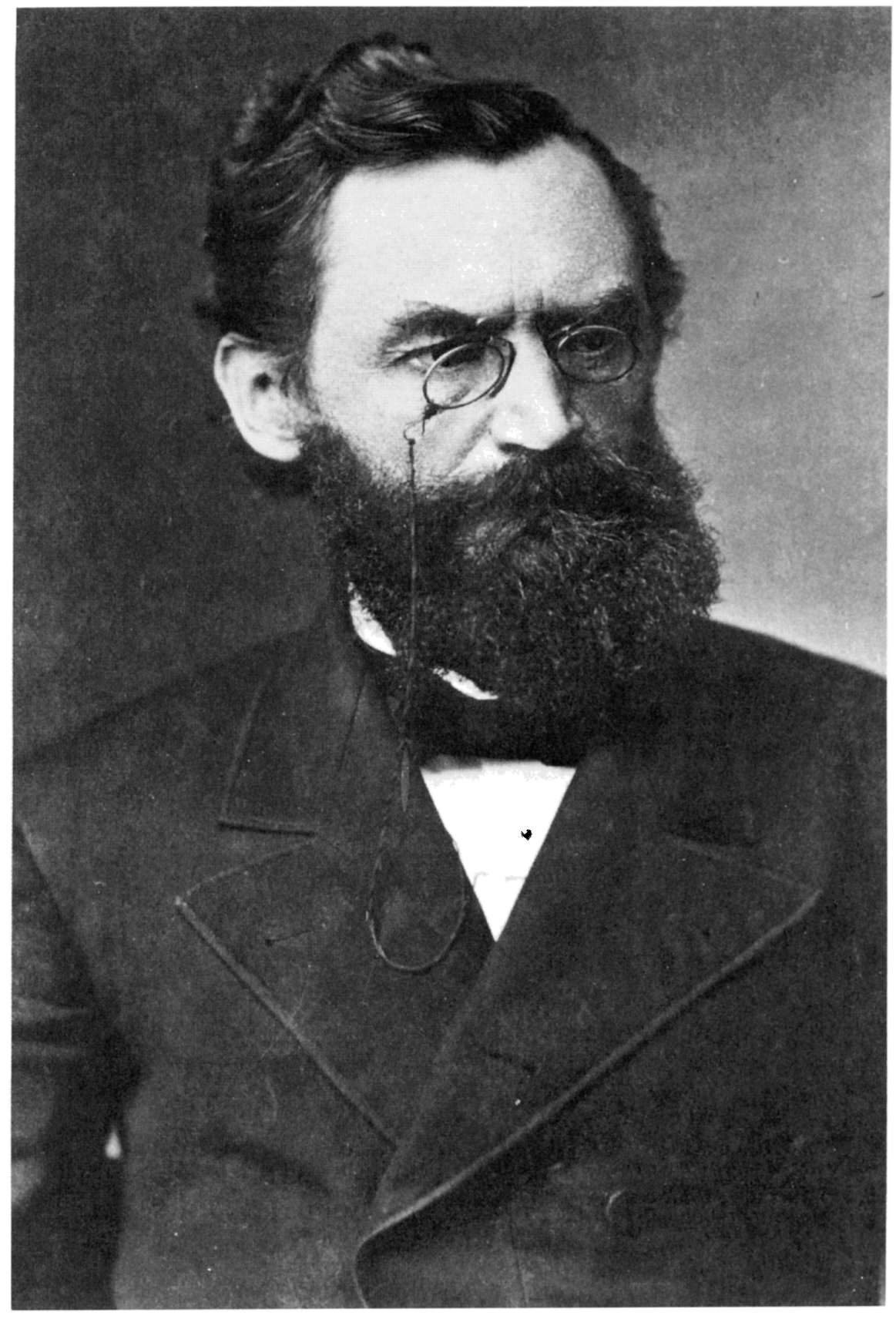




\title{
Sart Echun A Biography
}

\author{
by \\ Hans L. TREFousse
}

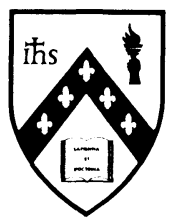

FORDHAM UNIVERSITY PRESS

NEW YORK

1998 
Copyright (C) 1998 by Fordham University Press

All rights reserved

LC 97-44229

ISBN 0-8232-1854-6 (hardcover)

ISBN 0-8232-1855-4 (paperback)

ISSN 1089-8719

The North's Civil War, no. 5

Library of Congress Cataloging-in-Publication Data

Trefousse, Hans Louis.

Carl Schurz, a biography / by Hans L. Trefousse.

p. cm. - (The North's Civil War, ISSN 1089-8719; no. 5)

Originally published: Knoxville : University of Tennessee Press.

c 1982.

Includes bibliographical references (p. ) and index.

ISBN 0-8232-1854-6 (hardcover). - ISBN 0-8232-1855-4 (paperback)

1. Schurz, Carl, 1829-1906. 2. Statesmen-United States-

-Biography. 3. United States. Congress. Senate-Biography.

4. Legislators-United States-Biography. 5. German Americans-Biography. I. Title. II. Series.

E664.S39T7 1998

$328.73^{\prime} 092-\mathrm{dc} 21$

[B]

$97-44229$

CIP

Frontispiece: Carl Schurz (Courtesy of Library of Congress)

Printed in the United States of America 
For Walter and Alberta Albersheim 
